\title{
Phylogenetic Analysis of Antibiotic Resistance Genes and Virulence Genes of Kebsiella species in silico
}

\author{
Nusrat Nahar and Ridwan Bin Rashid \\ Computational Chemistry and Bioinformatics Laboratory, Department of Pharmacy, State University of \\ Bangladesh, Dhaka-1205, Bangladesh
}

(Received: May 15, 2017; Accepted: June 11, 2017; Published (web): June 21, 2017)

\begin{abstract}
A total of twelve isolates were screened for virulence and antibiotic resistance genes associated with Klebsiella pneumoniae infections. Virulence and antibiotic resistance genes were detected by in silico PCR amplification. Iron uptake protein entB was detected in $66.67 \%(\mathrm{n}=8)$ of the isolates while no isolate was found to harbour chelating agent irp2. Iron uptake system $k f u$, involved in purulent tissue infections and capsule formation, was identified in $25 \%(\mathrm{n}=3)$ of the isolates. Regulator of mucoid phenotype A, rmpA was not found in any of the isolates. The wabG gene, responsible for urinary tract infections was found in seven K. pneumoniae strains. Five uge positive strains might play role in the pathogenicity of K. pneumoniae infections. About $83.33 \%$ of the isolates were positive for type 1 fimbriae fimH1 while no type 3 fimbriae $m r k D$ gene was found. Complement reaction blocked by plasmid traT gene was not observed in Klebsiella species while eight isolates harboured outer membrane lipoprotein, ycfM which protects Klebsiella species from antibiotics. Antibiotic resistance genes $b l a_{\mathrm{TEM}}$ and $b l a_{\mathrm{SHV}}$ were detected in $33.33 \%(\mathrm{n}=4)$ and $66.67 \%(\mathrm{n}=8)$ of the isolates while $25 \%$ isolates carried both $b l a_{\text {TEM }}$ and $b l a_{\text {SHV }}$ genes. Genotype 1 carried fimH1 and $y c f M$ genes while all the virulence genes studied were present in genotype 2 and 3 . The bla $a_{\mathrm{SHV}}$ gene was detected in all the genotypes while bla $a_{\text {TEM }}$ gene was found in only genotype 1 and 3 . The findings of this study would be helpful to predict virulence gene associated with Klebsiella infections. This data also helps us to choose antibiotics for treating Klebsiella infections. By assessing the genotypic distribution of antibiotic resistance gene, correct antibiotic can be used to treat the infection. This could help reduce emergence of antibiotic resistance since it is known that incorrect choice of antibiotics contributes to antibiotic resistance.
\end{abstract}

Key words: Klebsiella, virulence gene, antibiotic resistance gene, PCR, genotype.

\section{INTRODUCTION}

Pathogenic bacteria Klebsiella belongs to Enterobacteriaceae family and responsible for pneumonia, bacteremia, urinary tract infections, pyogenic liver abscesses, wounds and burns infections. ${ }^{1}$ Several studies reported that most of the nosocomial infections in Egypt were caused by Klebsiella species. ${ }^{2,3}$ Shon et al. reported a new hypermucoviscous K. pneumoniae strain in Asian countries that was responsible for communityacquired primary liver abscesses, endophthalmitis or metastatic meningitis. ${ }^{4}$ Western countries recognized

Correspondence to: Ridwan Bin Rashid

Email: ridwan@sub.edu.bd

Dhaka Univ. J. Pharm. Sci. 16(1): 119-127, 2017 (June) sporadic cases of $K$. pneumoniae infections as reported by Compain et al. ${ }^{5}$ The virulence factors, encoded by various virulence genes, determine the pathogenicity of $K$. pneumoniae infections and these virulence factors are responsible for many kinds of diseases through attacking the mammalian immune system. ${ }^{6}$ Several studies found biofilm formation, capsule synthesis, iron uptake, hypermucoviscosity, lipopolysaccharides formation as virulence factors which are involved in the pathogenicity of $K$. pneumoniae infections. ${ }^{7,8}$

The clinical features of $K$. pneumoniae infections mostly depend on the mode of actions of virulence factors encoded by virulence genes. Recent studies reported that $K$. pneumoniae was responsible for an acute liver abscess in China, Kuwait and Iraq. ${ }^{8,11}$ 
K. pneumoniae infections are particularly worrisome because of the resistance grown to most of the antibiotic drugs available, creating a serious situation reminiscent of the pre-antibiotic era. Antibioticresistant infections, therefore, are a substantial health and economic burden to patients and their families. Antibiotic resistant infections commonly occur due to extensive use of invasive procedures and abuse of antibiotics. Carbapenem-resistant Enterobacteriaceae (CRE) are a group of bacteria that have become resistant to nearly all available antibiotics, including carbapenems. Previously enterobacteriaceae infections were treated with carbapenems antibiotics $^{12}$ but prevalence of carbapenem-resistant Klebsiella species increased dramatically from 2001 to $2011 .{ }^{13}$ Gram-negative enterobacteriaceae such as Escherichia coli and K. pneumoniae harboured an enzyme called New Delhi metallo-beta-lactamase (NDM-1) which makes them resistant to virtually all beta-lactams, including carbapenems. Yeh et al. demonstrated that K. pneumoniae infections are hard to treat due to resistant properties to third generation cephalosporins like cefotaxime, ceftriaxone and ceftazidime. $^{14} \mathrm{~K}$. pneumoniae harbours plasmid encoded beta-lactamase genes (SHV, TEM and CTXM) which conferred resistance to many types of antibiotics. ${ }^{15}$ Antibiotic-resistant infections add considerable costs to the nation's already overburdened health care system. When first-line and then second-line antibiotic treatment options are limited or unavailable, health care professionals may be forced to use antibiotics that are more toxic to the patients and frequently more expensive. Coordinated efforts to implement new policies, renew research efforts, and pursue steps to manage the problem are greatly needed. As an alternative to in vitro methods for identifying bacteria, various in silico methods have been developed. In silico study in medicine is thought to have the potential to choose the effective antibiotics while reducing the need for expensive lab work and clinical trials.

The aim of this study was to characterize the prevalence of virulence and antibiotic resistance genes in 12 Klebsiella species. Pulsed-field gel electrophoresis (PFGE) analysis was used to assess the genotypic distribution of virulence and resistance genes of Klebsiella strains.

\section{MATERIALS AND METHODS}

Strains used in the study. Strains used in the study are summarized in Table 1.

Primers used in the study. Primers used for detection of antibiotic resistance genes are summarized in Tables 2 and 3.

Table 1. Name of the isolates.

\begin{tabular}{ll}
\hline $\begin{array}{l}\text { Sl. } \\
\text { No. }\end{array}$ & Isolate \\
\hline 1 & NC_018106 Klebsiella oxytoca E718 \\
2 & NC_016612 Klebsiella oxytoca KCTC 1686 \\
3 & NC_011283 Klebsiella pneumoniae 342 \\
4 & NC_022566 Klebsiella pneumoniae CG43 \\
5 & NC_022082 Klebsiella pneumoniae JM45 \\
6 & NC_016612 Klebsiella pneumoniae KCTC 2242 \\
7 & NC_012731 Klebsiella pneumoniae NTUH-K2044 \\
8 & NC_018522 Klebsiella pneumoniae subsp. pneumoniae \\
& $\begin{array}{l}\text { 1084 } \\
9\end{array}$ \\
& NC_016845 Klebsiella pneumoniae subsp. pneumoniae \\
10 & HS11286 \\
& NC_009648 Klebsiella pneumoniae subsp. pneumoniae \\
11 & $\begin{array}{l}\text { MGH 78578 } \\
\text { NC_021232 Klebsiella pneumoniae subsp. }\end{array}$ \\
& rhinoscleromatis strain SB3432 \\
12 & NC_013850 Klebsiella variicola At-22 \\
\hline
\end{tabular}

Table 2. Primers for detection of virulence genes.

\begin{tabular}{|c|c|c|}
\hline Gene & $\begin{array}{l}\text { Primer sequence } \\
\left(5^{\prime}-3{ }^{\prime}\right)\end{array}$ & $\begin{array}{l}\text { Amplicon } \\
\text { size (bp) }\end{array}$ \\
\hline entB & $\begin{array}{l}\text { ATTTCCTCAACTTCTGGGGC } \\
\text { AGCATCGGTGGCGGTGGTCA }\end{array}$ & $371^{7}$ \\
\hline irp-2 & $\begin{array}{l}\text { TCCCTCAATAAAGCCCACGCT } \\
\text { TCGTCGGGCAGCGTTTCTTCT }\end{array}$ & $287^{16}$ \\
\hline$k f u$ & $\begin{array}{l}\text { GAA GTG ACG CTG TTT CTG GC } \\
\text { TTT CGT GTG GCC AGT GAC TC }\end{array}$ & $797^{17}$ \\
\hline wabG & $\begin{array}{l}\text { CGGACTGGCAGATCCATATC } \\
\text { ACCATCGGCCATTTGATAGA }\end{array}$ & $683^{18}$ \\
\hline rmpA & $\begin{array}{l}\text { ACTGGGCTACCTCTGCTTCA } \\
\text { CTTGCATGAGCCATCTTTCA }\end{array}$ & $535^{14}$ \\
\hline uge & $\begin{array}{l}\text { TCT TCA CGC CTT CCT TCA CT } \\
\text { GAT CAT CCG GTC TCC CTG TA }\end{array}$ & $534^{19}$ \\
\hline fimH1 & $\begin{array}{l}\text { ATGAACGCCTGGTCCTTTGC } \\
\text { GCTGAACGCCTATCCCCTGC }\end{array}$ & $688^{7}$ \\
\hline$m r k D$ & $\begin{array}{l}\text { CCACCAACTATTCCCTCGAA } \\
\text { ATGGAACCCACATCGACATT }\end{array}$ & $226^{7}$ \\
\hline ycfM & $\begin{array}{l}\text { ATCAGCAGTCGGGTCAGC } \\
\text { CTTCTCCAGCATTCAGCG }\end{array}$ & $107^{7}$ \\
\hline $\operatorname{trt} T$ & $\begin{array}{l}\text { GGTGTGGTGCGATGAGCACAG } \\
\text { CACGGTTCAGCCATCCCTGAG }\end{array}$ & $288^{7}$ \\
\hline
\end{tabular}


Table 3. Primers for detection of antibiotic resistance genes.

\begin{tabular}{|c|c|c|}
\hline Gene & Primer sequence ( $\left.5^{\prime}-3{ }^{\prime}\right)$ & $\begin{array}{l}\text { Amplicon } \\
\text { size } \\
\text { bp }\end{array}$ \\
\hline$b l a_{\mathrm{SHV}}$ & $\begin{array}{l}\text { GGCCGCGTAGGCATGATAGA } \\
\text { CCCGGCGATTTGCTGATTTC }\end{array}$ & $714^{20}$ \\
\hline$b l a_{\mathrm{TEM}}$ & $\begin{array}{l}\text { CAGCGGTAAGATCCTTGAGA } \\
\text { ACTCCCCGTCGTGTAGATAA }\end{array}$ & $643^{20}$ \\
\hline$b l a_{\mathrm{VIM}}$ & $\begin{array}{l}\text { GTTTGGTCGCATATCGCAAC } \\
\text { AATGCGCAGCACCAGGATAG }\end{array}$ & $389^{21}$ \\
\hline$b l a_{\mathrm{IMP}}$ & $\begin{array}{l}\text { GAAGGCGTTTATGTTCATAC } \\
\text { GTACGTTTCAAGAGTGATGC }\end{array}$ & $587^{21}$ \\
\hline $\begin{array}{l}\text { bla }{ }_{\text {OXA- }} \\
48\end{array}$ & $\begin{array}{l}\text { GCGTGGTTAAGGATGAACAC } \\
\text { CATCAAGTTCAACCCAACCG }\end{array}$ & $438^{22}$ \\
\hline$b l a_{\mathrm{NDM}-1}$ & $\begin{array}{l}\text { GGTGCATGCCCGGTGAAATC } \\
\text { ATGCTGGCCTTGGGGAACG }\end{array}$ & $660^{23}$ \\
\hline
\end{tabular}

PCR amplification. An online software, http://insilico.ehu.eus/PCR/ was designed to perform in silico PCR amplification. ${ }^{24,25}$
PFGE digestion. Pulse-field gel electrophoresis (PFGE) digestion and construction of the dendrogram was done in silico using the website http://insilico.ehu.es/digest/. ${ }^{24,25}$ The enzyme used for the digestion was $X b a l$ and lambda ladder was used to compare the bands.

\section{RESULTS AND DISCUSSION}

Genetic diversity of the isolates was determined using pulsed field gel electrophoresis (PFGE) by $X b a I$ restriction digestion. This enzyme recognized the T'CTAG_A sequence and isolates clustered into four genotypic groups according to their banding patterns (Figure 1). Genotype 3 was found to be the most prevalent (50\%) followed by genotype $1(25 \%)$, $2(16.67 \%)$ and $4(8.03 \%)$ as shown in Figure 2.

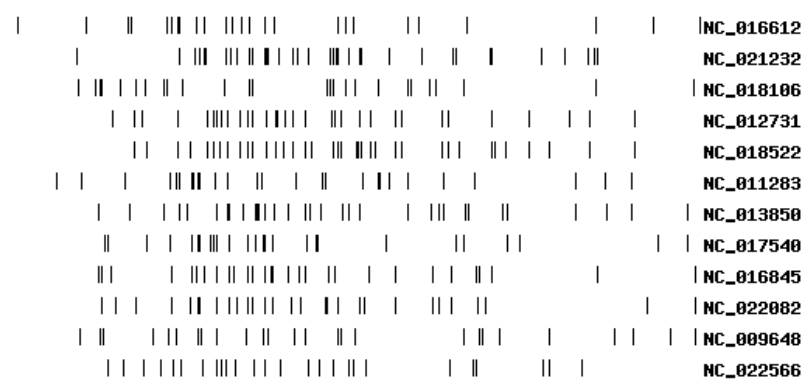

Dice distance / UPGMP

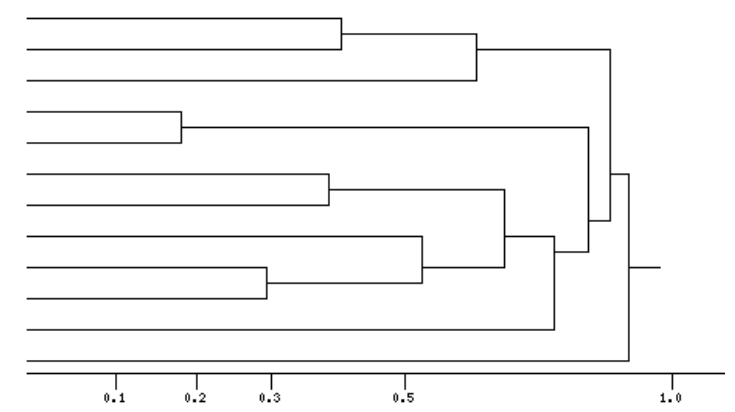

Figure 1. Phylogenetic diversity of Klebsiella species identified by PFGE.

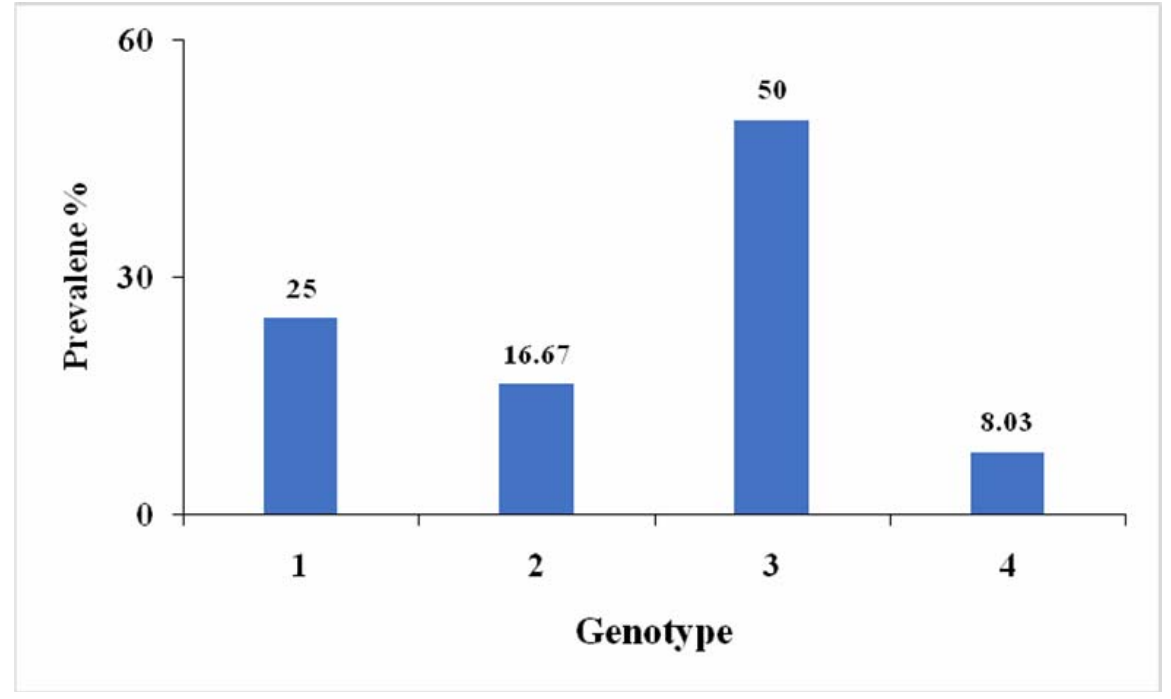

Figure 2. Prevalence of genotypes. 
A recent study documented that fungi and bacteria secreted iron chelating agents siderophores. ${ }^{6}$ Siderophore compounds enterobactin biosynthesis (entB) and yersiniabactin biosynthesis (irp-2) which are iron uptake proteins produced by Klebsiella. These chelating agents demonstrated higher affinity to extracellular ferric ions. ${ }^{6}$ May and Okabe suggested that biofilm formation is induced by the expression of enterobactin. ${ }^{26}$ Another study also found that ironenterobactin genes are activated when bacterial infections occurred. ${ }^{27}$ Aljanaby et al. documented that all isolates were found to be positive for enterobactin, entB gene but yersiniabactin, irp-2 was found in only 12 isolates. $^{6}$ Eight isolates $(66.67 \%)$ were found to harbour enterobactin gene, entB and gave $371 \mathrm{bp}$ gene product in the present study among them seven were $K$. pneumoniae.
Several studies also found that entB gene was present in almost all $\mathrm{K}$. pneumoniae. ${ }^{7,28,29}$ Another important iron uptake system, $k f u$ is involved in purulent tissue infections and capsule formation was reported by Aher et al. ${ }^{30}$ Aljanaby et al. found that about $65.62 \%$ isolates had the $k f u$ gene. ${ }^{6}$ Three $K$. pneumoniae isolates were found to harbour iron uptake system, $k f u$ with 797 bp gene product. No yersiniabactin biosynthesis (irp-2) gene was found. Genotypic distribution found that genotype 1 contained no ent $B$ or kfu gene (Figure 3). Genotype 2 contained both entB and $k f u$ genes (100\%) while genotype 4 harboured only entB genes (100\%). About $83.33 \%$ isolates present in genotype 3 expressed entB genes while around $16.67 \%$ isolates in genotype 3 carried $k f u$ genes.

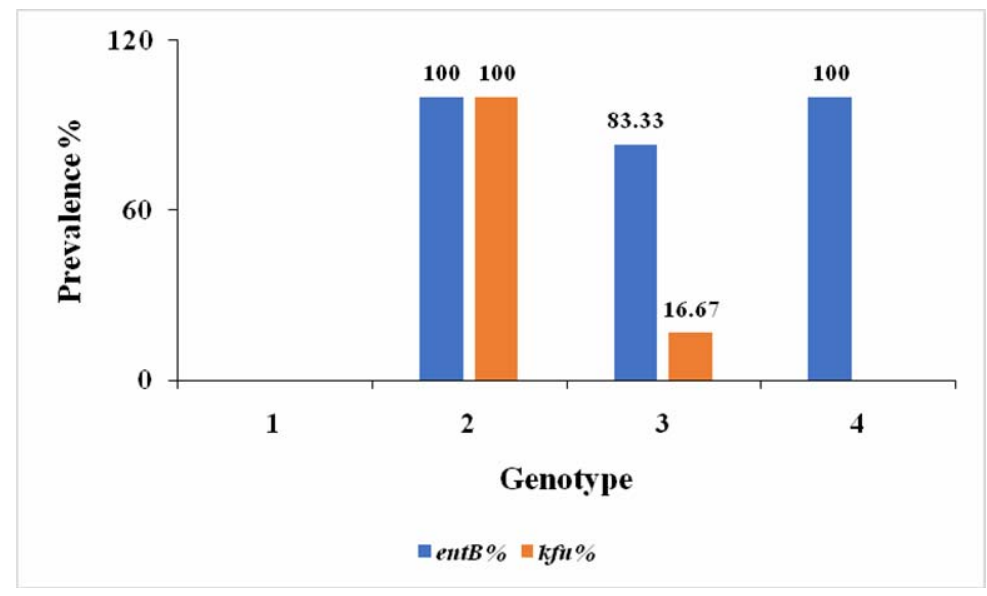

Figure 3. Genotypic distribution of entB and $k f u$ genes.

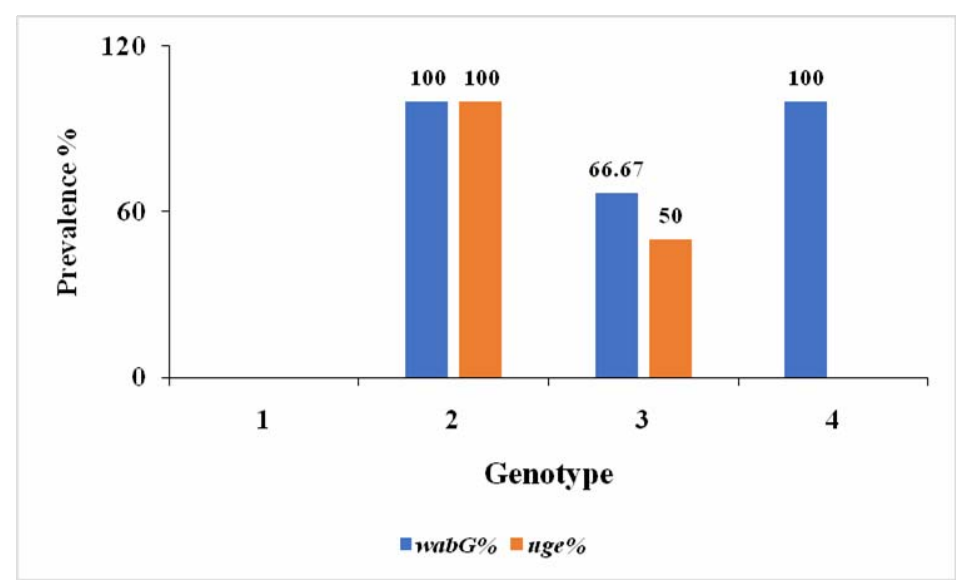

Figure 4. Genotypic distribution of $w a b G$ and $u g e$ gene 
A previous study documented that virulent strains of $K$. pneumoniae produced mucopolysaccharide mass and extracellular polysaccharides. ${ }^{31}$ Another study found that $\mathrm{rmpA}$ gene caused invasive syndrome and also found that $90 \%$ of the isolates had rmpA gene in people with community acquired pneumonia in South Africa and Taiwan. ${ }^{32}$ Laboratory animal injected with mucoid strains of rmpA had higher mortality rate than animals injected with non-mucoid strains in the same laboratory. ${ }^{32}$ Rivero et al. reported that strongly mucoviscous phenotype plasmid controlled the rmpA gene which is responsible for the synthesis of the regulator of the capsular polysaccharide. ${ }^{33}$ In the study conducted by Aljanaby et al. 20 isolates (62.5\%) had the rmpA gene out of the 32 strains studied. ${ }^{6}$ The present study found no rmpA gene. An earlier study reported that wabG gene is associated with invasive and serious infections but their mechanism in disease development is still unclear. ${ }^{34}$ Mutant wabG gene produced non-capsulated and less virulent $K$. pneumoniae strains in murine pneumonia model. Mutant wabG gene produced defective core polysaccharides and was unable to induce urinary tract infection that proved an important role in the pathogenicity of $K$. pneumoniae infections. ${ }^{35}$ Aljanaby et al. documented that about $87.5 \%$ of the isolates harboured wabG gene. ${ }^{6}$ Seven K. pneumoniae strains produced $683 \mathrm{bp}$ gene product for wabG gene in the present study. So, these isolates might be involved in urinary tract infections. Previous findings reported that laboratory animals harbouring $K$. pneumoniae strains without uge were less virulent than strains with uge gene. ${ }^{19}$ Present study found five (41.67\%) uge positive K. pneumoniae strains. Genotype 1 contained no virulence genes. All the isolates present in genotype 2 carried wabG and uge genes but genotype 4 contained only wabG genes (Figure 4). Prevalence of wabG and uge genes was varied in genotype 3. The prevalence of $w a b G$ and uge genes in genotype 3 was $66.67 \%$ and $50 \%$, respectively.
Adhesive organelles fimH1 involved in urinary tract infections was documented by Struve et al. ${ }^{36}$ Type 1 fimbriae, fimH1 was detected in $83.33 \%$ of the isolates and produced 688 bp gene product. $K$. pneumoniae binds to endothelial cells and epithelial cells of the respiratory and urinary tracts with the help of type 3 fimbrial adhesion, $m r k D$ gene. Langstraat et al. found that this gene binds to collagen molecules of the mammalian cells. ${ }^{37}$ Sahly et al. stated that type 1 and type 3 fimbriae were found in clinical K. pneumoniae isolates. ${ }^{38}$ Recent study found that all isolates from wound and blood samples contained type 1 , fimH1 and type 3 fimbriae, $m r k D$ gene. ${ }^{39}$ They also identified that isolates from sputum samples harboured type 1 fimbriae, fimH1 while isolates from urine samples contained mainly type 3 fimbriae, $m r k D$ gene. Present study found no $m r k D$ gene. Biofilm formation capacity of Klebsiella helps to colonize in the urinary tract and is involved in chronic urinary tract infections. ${ }^{6}$ Bellifa et al. found that biofilm protects bacteria from drug exposure and bacteria harbouring this biofilm forming gene are more resistant to antimicrobials. ${ }^{40}$ El Fertas-Aissani et al. stated that complement reaction is blocked by plasmidic traT gene and this gene also play a role in bacterial conjugation. ${ }^{7}$ Recent study found high level of traT gene $(78.5 \%)$ in K. pneumoniae isolates. ${ }^{39}$ However, no traT gene was detected in the present study. Aljanaby et al. found that all the isolates they studied harbouredouter membrane protein, $y c f M{ }^{6}$ Klebsiella is protected from drug exposure with the help of outer membrane lipoprotein, $y c f M .^{40}$ Eight isolates were detected to harbor $y c f M$ gene with 160 bp gene product. Type 1 fimbriae, fimH1 and outer membrane lipoprotein, $y c f M$ genes were present in all genotypes (Figure 5). Their distribution within the genotype was almost similar. All the isolates present in genotype 2 and 4 carried fimH1 and ycfM genes. About 33.33\% isolates in genotype 1 expressed fimH1 and $y c f M$ genes. The fimH1 gene was encountered at higher prevalence (100\%) in genotype 3 while about $66.66 \%$ isolates in genotype 3 carried ycfM genes. 
Resistance to beta-lactam antibiotics is acquired due to the presence of beta-lactamase gene. $K$. pneumoniae have acquired amoxicillin, ampicillin and ticarcillin resistance genes naturally. ${ }^{6}$ Several studies found that K. pneumoniae harbouring AmpC beta-lactamases, metallo enzymes, SHV, extendedspectrum $\beta$-lactamases, and TEM beta-lactamases conferred resistance to meropenem, imipenem, $3^{\text {rd }}$ generation cephalosporins and others. ${ }^{22,41,42}$ Efflux pump is also important for virulence of Klebsiella. ${ }^{43}$

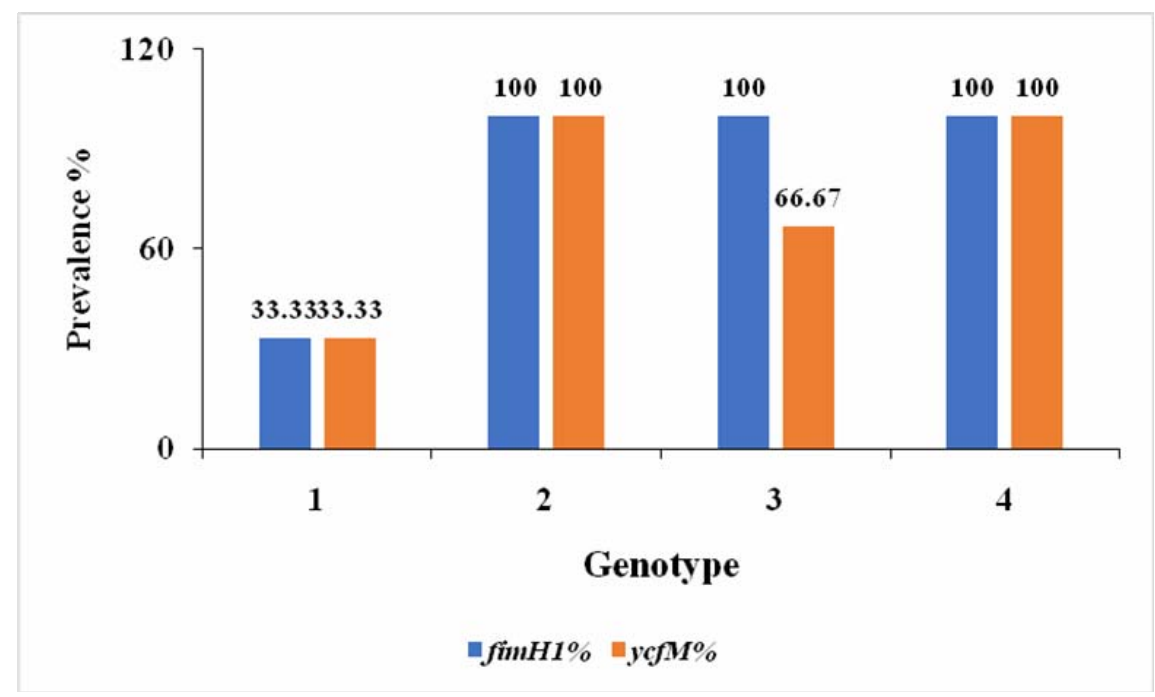

Figure 5. Genotypic distribution of fimH1 and $y c f M$ genes.

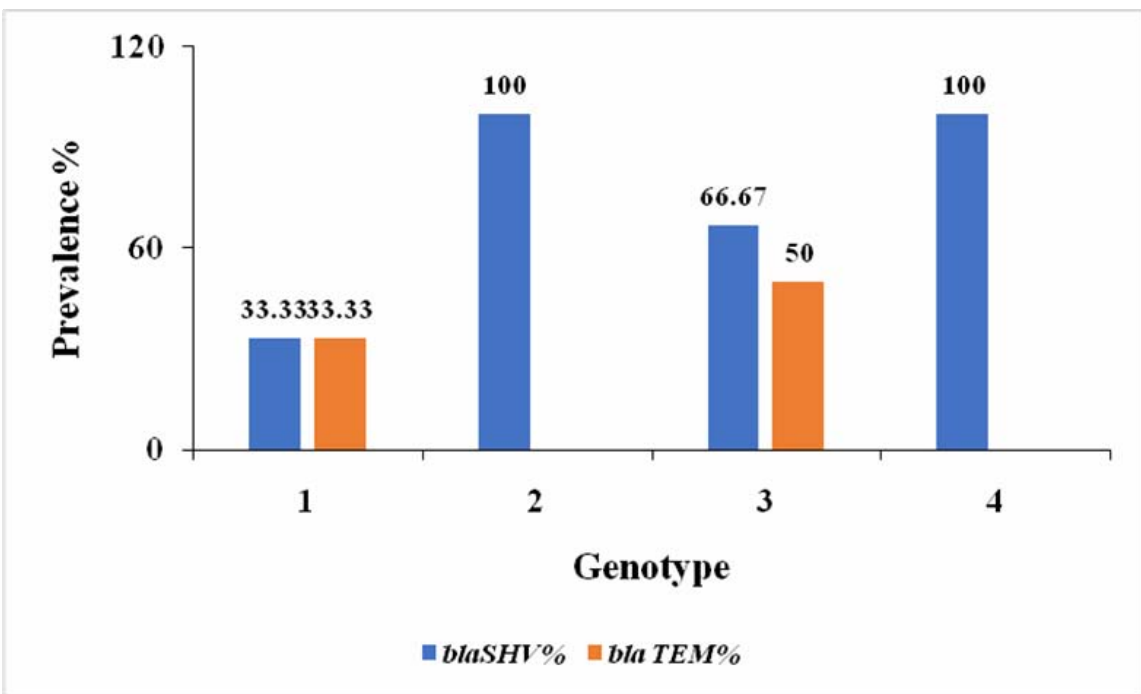

Figure 6. Genotypic distribution of $b l a_{\mathrm{SHV}}$ and $b l a_{\mathrm{TEM}}$ genes.

Another researcher identified the correlation of ESBL genes with virulence factors. ${ }^{31}$ Present study detected four $(33.33 \%) b l a_{\mathrm{TEM}}$ and eight $(66.67 \%) b l a_{\mathrm{SHV}}$ genes. The $b l a_{\mathrm{TEM}}$ and $b l a_{\mathrm{SHV}}$ gene produced $643 \mathrm{bp}$ and $714 \mathrm{bp}$ gene product, respectively. Twenty-five percent isolates carried both $b l a_{\mathrm{TEM}}$ and $b l a_{\mathrm{SHV}}$ genes.
Poirel et al. reported that Turkey first observed OXA48 gene in $K$. pneumoniae. ${ }^{22} K$. pneumonia harbouring this OXA-48 gene was then spread to European countries and Mediterranean countries. ${ }^{44}$ New Delhi first reported clinically significant carbapenemase producer NDM-1 (New Delhi 
metallo- $\beta$-lactamase) $)^{45}$ which was spread to other countries. ${ }^{46}$ Morocco $^{47}$, Oman $^{46}$, Singapore ${ }^{48}$ and the United States ${ }^{49}$ identified co-existing NDM-1 and OXA group carbapenemases gene in Klebsiella isolates. Recent study found that $58 \%$ isolates had OXA-48 genes and 2\% harboured NDM-1 gene while NDM- 1 and OXA-48 genes were present in 8\% of the isolates. ${ }^{50}$ Non-glucose-fermenting bacteria like Pseudomonas aeruginosa was found to harbor $b l a_{\mathrm{VIM}}$ and $b l a_{\mathrm{IMP}}$ gene $^{51}$ but a recent study detected no $b l a_{\mathrm{VIM}}$ and $b l a_{\mathrm{IMP}}$ in $K$. pneumoniae. ${ }^{52}$ China, Japan and Australia had identified IMP-producing members of the Enterobacteriaceae while isolates from Italy and Greece were found to harbour VIMproducing enterobacteriaceae. ${ }^{44}$ Antibiotic resistance gene was present in all genotypes (Figure 6). All the isolates present in genotype 2 and 4 carried bla $a_{\mathrm{SHV}}$ genes $(100 \%)$. Genotype 1 and 3 carried both $b l a_{\mathrm{SHV}}$ and $b l a_{\text {TEM }}$ genes. About $33.33 \%$ isolates present in genotype 3 expressed both $b l a_{\mathrm{SHV}}$ and $b l a_{\mathrm{TEM}}$ genes. On the other hand, about 66.67 and 50\% isolates in genotype 3 harboured $b l a_{\mathrm{SHV}}$ and $b l a_{\mathrm{TEM}}$ genes, respectively.

\section{CONCLUSION}

Klebsiella species harboured six virulence genes out of the ten in our study. About $16.67 \%$ of the isolates carried six virulence genes while about $33.33 \%$ isolates expressed four virulence genes. The fimH1, $y c f M$ and entB genes were commonly detected in all the isolates studied. Twenty-five percent isolates carried both $b l a_{\mathrm{TEM}}$ and $b l a_{\mathrm{SHV}}$ genes. Antimicrobial resistance has emerged over last few decades due to abuse of antibiotic drugs. Antibiotic development is no longer considered to be economically feasible since antibiotics are used for relatively short periods and are not profitable to treat chronic conditions such as diabetes, psychiatric disorders, gastroesophageal reflux or asthma. Resistance regarding antibiotic abuse has been suggested by many microbiologists and infectiousdisease specialists. Before prescribing a new antibiotic, physicians would be suggested to reserve it for only the worst cases. It is also suggested to prescribe the old antibiotics by analyzing the resistance pattern. So, new antibiotics can be considered as 'last line' drugs to combat serious infectious illnesses. This study helps to predict resistance based on genotype and aids in the selection of antibiotic would be the most effective for treating Klebsiella infections.

\section{REFERENCES}

1. Rahamathulla, M.P., Harish, B.N., Mataseje, L. and Mulvey, M.R. 2016. Carbapenem resistance mechanisms among blood isolates of Klebsiella pneumoniae and Escherichia coli. Afr. J. Microbiol. Res.10, 45-53.

2. Daef, E.A. and Elsherbiny, N.M. 2012. Clinical and microbiological profile of nosocomial infections in adult intensive care units at Assiut University hospitals, Egypt. $J$. Am. Sci. 8, 1239-1250.

3. Abdel-Wahab, F., Ghoneim, M., Khashaba, M., El-Gilany, A.H. and Abdel-Hady, D. 2013. Nosocomial infection surveillance in an Egyptian neonatal intensive care unit. $J$. Hosp. Infect. 83, 196-199.

4. Shon, A.S., Bajwa, R.P.S. and Russo, T.A. 2013. Hypervirulent (hypermucoviscous) Klebsiella pneumoniae: a new and dangerous breed. Virulence 4, 107-118.

5. Compain, F., Babosan, A., Brisse, S., Genel, N., Audo, J., Ailloud, F., Kassis-Chikhani, N., Arlet, G. and Decré, D. 2014. Multiplex PCR for detection of seven virulence factors and $\mathrm{K} 1 / \mathrm{K} 2$ capsular serotypes of Klebsiella pneumoniae. J. Clin. Microbiol. 52, 4377-4380.

6. Aljanaby, A.A. and Alhasani, A.H. 2016. Virulence factors and antibiotic susceptibility patterns of multidrug resistance Klebsiella pneumoniae isolated from different clinical infections. Afr.J. Microbiol. Res. 10, 829-43.

7. El Fertas-Aissani, R., Messai, Y., Alouache, S. and Bakour, R. 2013. Virulence profiles and antibiotic susceptibility patterns of Klebsiella pneumonia strains isolated from different clinical specimens. Pathol. Biol. 61, 209-216.

8. Chung, T.H., Karkey, A., Pham, T.D., Boinett, C.J., Cain, A.K. and Ellington, M. 2015. A high-resolution genomic analysis of multidrug resistant hospital outbreaks of Klebsiella pneumoniae. EMBO Mol. Med. 7, 227-39.

9. Lawlor, M.S., O'Connor, C. and Miller, V.L. Yersiniabactin is a virulence factor for Klebsiella pneumoniae during pulmonary infection. Infect. Immun. 75, 14631472.

10. Wu, C.C., Wang, C.K., Chen, Y.C., Lin, T.H., Jinn, T.R. and Lin, C.T. 2014. IscR regulation of capsular polysaccharide biosynthesis and iron-acquisition systems in Klebsiella pneumoniae CG43. PloS one. 9, e107812. 
11. Christopher, A.B., Michelle, P. and Virginia, L.M. 2014. Klebsiella: A long way to go towards understanding this enigmatic jet-setter. F1000 Prime Rep. 6, 64.

12. Vardakas, K.Z., Tansarli, G.S., Rafailidis, P.I. and Falagas, M.E. 2012. Carbapenems versus alternative antibiotics for the treatment of bacteraemia due to Enterobacteriaceae producing extended-spectrum $\beta$-lactamases: a systematic review and meta-analysis. J. Antimicrob. Chemother. 67, 27932803.

13. CDC. 2013. Vital Signs: Carbapenem-Resistant Enterobacteriaceae. 165170 (Center for Disease Control and prevention (CDC).

14. Yeh, K.M., Kurup, A., Siu, L.K., Koh, Y.L., Fung, C.P., Lin, J.C., Chen, T.L., Chang, F.Y. and Koh, T.H. 2007. Capsular serotype $\mathrm{K} 1$ or $\mathrm{K} 2$, rather than magA and rmpA, is a major virulence determinant for Klebsiella pneumoniae liver abscess in Singapore and Taiwan. J. Clin. Microbiol. 45, 466-471.

15. Ahmed, O.I., Soha, A.E., Tamer, M.A. and Iman, Z.A. 2014. Detection of bla $a_{\mathrm{SHV}}$ and $b l a_{\mathrm{CTX}-\mathrm{M}}$ genes in ESBL producing Klebsiella pneumoniae isolated from Egyptian patients with suspected nosocomial infections. Egypt. J. Med Hum. Genet .14, 277-283.

16. Schubert, S., Cuenca, S., Fischer, D. and Heesemann, J. 2000. High pathogenicity island of Yersinia pestis in Enterobacteriaceae isolated from blood cultures and urine samples: prevalence and functional expression. J. Infect. Dis. 182, 1268-1271.

17. Ma, L.C., Fang, C.T., Lee, C.Z., Shun, C.T. and Wang, J.T. 2005. Genomic heterogeneity in K. pneumoniae strains is associated with primary pyogenic liver abscess and metastatic infection. J. Infect. Dis. 192, 117-128.

18. Brisse, S., Fevre, C. and Passet, V. 2009. Virulent clones of Klebsiella pneumoniae: identification and evolutionary scenario based on genomic and phenotypic characterization. PLoS One. 4, e4982

19. Regué, M., Hita, B., Piqué, N., Izquierdo, L., Merino, S., Fresno, S., Benedí, V.J. and Tomás, J.M. 2004. A Gene uge is essential for Klebsiella pneumoniae virulence. Infect. Immun. 72, 54-61.

20. Ensor, V.M., Jamal, W., Rotimi, V.O., Evans, J.T. and Hawkey, P.M. 2009. Predominance of CTX-M-15 extended spectrum beta-lactamases in diverse Escherichia coli and Klebsiella pneumoniae from hospital and community patients in Kuwait. Int. J. Antimicrob. Agents 33, 487-489.

21. Pitout, J.D. and Laupland, K.B. 2008. Extended-spectrum $\beta$ lactamase-producing Enterobacteriaceae: an emerging public-health concern. Lancet. Infect. Dis. 8, 159-66.
22. Poirel, L., Walsh Timothy, R., Cuvillier, V. and Nordmann, P. 2011. Multiplex PCR for detection of acquired carbapenemase genes. Diagn. Microbiol. Infect. Dis. 70, 119123.

23. Mulvey, M.R., Grant, J.M., Plewes, K., Roscoe, D. and Boyd, D.A. 2011. New Delhi metallo- $\beta$-lactamase in Klebsiella pneumoniae and Escherichia coli, Canada. Emerg. Infect. Dis. 17, 103-6.

24. San Millán, R.M., Martínez-Ballesteros, I., Rementeria, A., Garaizar, J. and Bikandi, J. 2013. Online exercise for the design and simulation of PCR and PCR-RFLP experiments. BMC Res. Notes 6, 513.

25. Bikandi, J., San Millán, R., Rementeria, A. and Garaizar, J. 2004. In silico analysis of complete bacterial genomes: PCR, AFLP-PCR and endonuclease restriction. Bioinformatics 20, 798-799.

26. May, T. and Okabe, S. 2011. Enterobactin is required for biofilm development in reduced genome Escherichia coli. Environ. Microbiol. 13, 3149-62.

27. Lai, Y.C., Peng, H.L. and Chang, H.Y. 2001. Identification of genes induced in vivo during Klebsiella pneumoniae CG43 infection. Infect. Immun. 69, 7140-5.

28. Podschun, R., Sievers, D., Foscher, A. and Ullmann, U. 1993. Serotypes, hemagglutinins, siderophore synthesis, and serum resistance of Klebsiella isolates causing human urinary tract infections. J. Infect Dis. 168, 1415-1421.

29. Koczura, R. and Kaznowski, A. 2003. Occurrence of the Yersinia high pathogenicity island and iron uptake systems in clinical isolates of Klebsiella pneumoniae. Microb. Pathog. 35, 197-02.

30. Aher, T., Roy, A. and Kumar, P. 2012. Molecular detection of virulence genes associated with pathogenicity of Klebsiella spp. isolated from the respiratory tract of apparently healthy as well as sick goats. Isr. J. Vet. Med. 67, $249-52$.

31. Wiskur, B.J., Hunt, J.J. and Callegan, M.C. 2008. Hypermucoviscosity as a virulence factor in experimental Klebsiella pneumoniae endophthalmitis. Invest. Ophthalmol. Vis. Sci. 49, 4931-4938.

32. Victor, L.Y., Dennis, S.H., Wen, C.K., Asia, S. and Keith, P.K. 2007. Virulence characteristics of Klebsiella and clinical manifestations of $K$. pneumoniae bloodstream infections. Emer. Infect. Dis. 13, 986- 93.

33. Rivero, A., Gomez, E., Alland, D., Huang, D. and Chiang, T. 2010. K2 serotype Klebsiella pneumoniae causing a liver abscess associated with infective endocarditis. J. Clin. Microbiol. 48, 639-641. 
34. Turton, J.F., Perry, C., Elgohari, S. and Hampton, C.V. 2010. PCR characterization and typing of Klebsiella pneumoniae using capsular type-specific, variable number tandem repeat and virulence gene targets. J. Med. Microbiol. 59, 541-547.

35. Izquierdo, L., Coderch, N., Piqué, N., Bedini, E., Corsaro, M.M., Merino, S., Fresno, S., Tomás, J.M. and Regué, M. 2003.The Klebsiella pneumoniae wabG gene: role in biosynthesis of the core lipopolysaccharide and virulence. $J$. Bacteriol. 185, 7213-7221.

36. Struve, C., Bojer, M. and Krogfelt, K.A. 2008. Characterization of Klebsiella pneumoniae type 1 fimbriae by detection of phase variation during colonization and infection and impact on virulence. Infect. Immun. 76, 4055-4065.

37. Langstraat, J., Bohse, M. and Clegg, S. 2001. Type 3 fimbrial shaft (MrkA) of Klebsiella pneumoniae, but not the fimbrialadhesin (MrkD), facilitates biofilm formation. Infect. Immun. 69, 5805-5812.

38. Sahly, H., Navon-Venezia, S., Roesler, L., Hay, A., Carmeli, Y., Podschun, R., Hennequin, C., Forestier, C. and Ofek, I. 2008. Extended-spectrum $\beta$-lactamase production is associated with an increase in cell invasion and expression of fimbrialadhesins in Klebsiella pneumoniae. Antimicrob. Agents Chemother. 52, 3029-3034.

39. Wasfi, R., Elkhatib, W.F. and Ashour, H.M. 2016. Molecular typing and virulence analysis of multidrug resistant Klebsiella pneumoniae clinical isolates recovered from Egyptian hospitals. Sci. Rep. 6.

40. Bellifa, S., Hassaine, H., Balestrino, D., Charbonnel, N., M'hamedi, I., Terki, I.K., Lachachi, M., Didi, W. and Forestier, C. 2013. Evaluation of biofilm formation of Klebsiella pneumoniae isolated from medical devices at the University Hospital of Tlemcen, Algeria. Afr. J. Microbiol. Res. 7, 5558-5564.

41. Moland, E.S., Hanson, N.D., Herrera, V.L., Black, J.A., Lockhart, T., Hossain, J., Johnson, J.A., Goering, R.V. and Thomson, K.S. 2003. Plasmid-mediated, carbapenemhydrolysing B-lactamase, KPC-2, in Klebsiella pneumoniae isolates. J. Antimicrob. Chemother. 51, 711-14.

42. Essack, S.Y., Hall, L.M. and Livermore, D.M. 2004. Klebsiella pneumoniae isolate from South Africa with multiple TEM, SHV and Amp Cbetalactamases. Int. J. Antimicrob. Agents. 23, 398-400.

43. Padilla, E., Llobet, E., Dome'nech-Sa'nchez, A., Martı'nezMartı'nez, L., Bengoechea, J.A. and Albertı, S. 2010. Klebsiella pneumoniae AcrAB efflux pump contributes to antimicrobial resistance and virulence. Antimicrob. Agents Chemother. 54, 177-183.
44. Nordmann, P., Naas, T. and Poirel, L. 2011. Global Spread of carbapenemase-producing Enterobacteriaceae. Emerg. Infect. Dis. 17, 1791-1798.

45. Yong, D., Toleman, M.A. and Giske, C.G. 2009. Characterization of a new metallo- $\beta$-lactamase gene, bla NDM-1, and a novel erythromycin esterase gene carried on a unique genetic structure in Klebsiella pneumoniae sequence type 14 from India. Antimicrob. Agents Chemother. 53, 50465054.

46. Dortet, L., Poirel, L., Al Yaqoubi, F. and Nordmann, P. 2012. NDM-1, OXA- 48 and OXA-181 carbapenemase-producing Enterobacteriaceae in Sultanate of Oman. Clin. Microbiol. Infect. 18, E144-E148.

47. Abouddihaj, B., El Otmani, F., El Yaagoubi F.L., Zerouali, K.T.M. and Timinouni, M. 2012. First report of a Klebsiella pneumoniae strain coproducing NDM-1, VIM-1 and OXA-48 carbapenemases isolated in Morocco. APMIS. 121, 675-677.

48. Balm, M.N.D., La, M.V., Krishnan, P., Jureen, R., Lin, R.T.P. and Teo, J.W.P. 2013. Emergence of Klebsiella pneumoniae co-producing NDM-type and OXA-181 carbapenemases. Clin. Microbiol. Infect. 19, E421-E423.

49. Doi, Y., O'Hara, J.A., Lando, J.F., Querry, A.M., Townsend, B.M., Pasculle, A.W. and Muto, C.A. 2014. Co-Production of NDM-1 and OXA-232 by Klebsiella pneumoniae. Emerg. Infect. Dis. 20, 163-164.

50. Candan, E.D. and Aksöz, N. 2015. Klebsiella pneumoniae: characteristics of carbapenem resistance and virulence factors. Acta. Biochim. Pol. 62, 867-874.

51. Toval, F., Guzmán-Marte, A., Madriz, V., Somogyi, T., Rodríguez, C. and García, F. 2015. Predominance of carbapenem-resistant Pseudomonas aeruginosa isolates carrying bla $_{\mathrm{IMP}}$ and bla $_{\mathrm{VIM}}$ metallo- $\beta$-lactamases in a major hospital in Costa Rica. J. Med. Microbiol. 64, 37-43.

52. Flores, C., Romão, C.M.C., Bianco, K., Miranda, C.C.D., Breves, A., Souza, A.P.S., Santos, R.M.R., Fonseca, B.O., Filippis, I.D. and Clementino, M.M. 2016. Detection of antimicrobial resistance genes in beta-lactamase-and carbapenemase-producing Klebsiella pneumoniae by patient surveillance cultures at an intensive care unit in Rio de Janeiro, Brazil. J. Bras. Patol. Med. Lab. 52, 284-292. 